\title{
Chronologia zmian w zaleceniach jakościowych złączy spawanych obciążonych dynamicznie według norm europejskich
}

\author{
Chronology of changes in quality recommendations \\ for dynamically loaded welded joints \\ according to European standards
}

\section{Streszczenie}

Integracja Polski z Unią Europejską powoduje konieczność zharmonizowania przepisów krajowych z przepisami europejskimi. Wymagania jakościowe złączy spawanych w mostach stalowych wg nowych zaleceń przedstawili autorzy w 11 publikacjach wydanych w latach $2002 \div 2017$. Określone tam wymogi normowe w wielu przypadkach poddano krytycznej ocenie. Próbę rekapitulacji zaleceń konstrukcyjno-projektowych oraz badawczych, dotyczących złączy spawanych w mostach, przedstawionych w tych publikacjach omówiono w artykule.

Słowa kluczowe: mosty stalowe; spawanie; złącza spawane

\begin{abstract}
The integration of Poland with the European Communities induced the necessity for harmonization of national regulations with European ones. Quality requirements for welded joints in steel bridges were presented by the authors in 11 articles published in the years $2002 \div 2017$. Standard requirements given there were subjected to critical remarks in many cases. The effort for recapitulation of structural and research recommendations for welded joints in bridges are presented in this paper.
\end{abstract}

Keywords: steel bridges; welding; welded joints

\section{Wstęp}

Wykonywanie złącza spawanego zawsze jest związane z możliwością wystąpienia niezgodności spawalniczych (NS). Należy uwzględniać powstałe odchylenia typu geometrycznego i metalurgicznego od parametrów złącza idealnego. Podstawową sprawą jest określenie dopuszczalnej wielko-

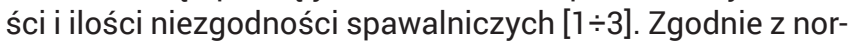
mą dla mostów stalowych PN-89/S-10050 [4], w konstrukcjach tych „wszystkie spoiny czołowe należy prześwietlić na całej ich długości" i zakwalifikować do odpowiedniej klasy wadliwości. Stosowana norma PN-87/M-69772 [5] przewidywała 5 klas wadliwości, a zaliczenie złącza do określonej klasy zależało od rodzaju wad, ich wielkości i stopnia nasilenia. Złącze w klasie wadliwości $\mathrm{R} 1$ było najmniej wadliwe, zaś w klasie R5 najbardziej wadliwe.

\section{Ocena jakości złączy spawanych wg norm europejskich}

Konieczność zharmonizowania przepisów krajowych z przepisami europejskimi [6] wynika z członkostwa PKN, od 1 stycznia 2004 r., w Europejskim Komitecie Normalizacyjnym (CEN). Zalecenia Międzynarodowego Instytutu Spawalnictwa (MIS) już w roku 2002 [7] wymagały, aby wszystkie złącza i spoiny projektowane $z$ uwzględnieniem zmęczenia spełniały wymagania jakościowe poziomu B wg EN 25817:1992 [8]. Norma ta od roku 2007 posiada znowelizowaną wersję wydaną jako PN-EN ISO 5817 [9]. Dokładnie wszystkie zmiany wprowadzone przez tę normę, przy ocenie niezgodności spawalniczych (NS), omówiono w [10].

Gwarantem dobrego wykonania konstrukcji spawanej powinna być jej realizacja w zakładach zakwalifikowanych do odpowiednich klas wykonania. W PN-EN 1090-2 [11], pierwotne wydanie w 2009, podano cztery klasy wykonania, od najmniej rygorystycznej - EXC1 do najbardziej wymagającej - EXC4 (tabl. I). Wykaz wymagań związanych z powyższymi klasami wykonania przedstawiono w tablicy A3 normy. W mostach należy dobierać klasę wykonania na podstawie rodzaju konstrukcji i występujących oddziaływań. Zaleca się przyjmować klasy EXC2 i EXC3 oraz w przypadku uzasadnionym klasę EXC4. Spawanie powinno być wykonywane według instrukcji technologicznej spawania (WPS), a badania nieniszczące (NDT) spoin należy prowadzić dwuetapowo.

Dr inż. Janusz Hołowaty; dr hab. inż. Bernard Wichtowski, em. prof. ZUT - Zachodniopomorski Uniwersytet Technologiczny w Szczecinie.

Autor korespondencyjny/Corresponding author: jah@wp.pl 
Etap I dotyczy wykonanych pierwszych pięciu złączy, których zakres badań jest dwukrotnie większy niż podany w tablicy II ( $\min 5 \%$, max $100 \%)$, a minimalna badana długość spoiny wynosi $900 \mathrm{~mm}$. W przypadku stwierdzenia niezgodności spawalniczych należy ustalić i usunąć przyczynę ich występowania oraz wykonać badanie nowego zestawu pięciu złączy.

Etap II dotyczy kolejnych spoin czołowych o zakresie badań w zależności od wartości występujących w nich naprężeń (por. tabl. II), przy minimalnej długości odcinka partii badanej $900 \mathrm{~mm}$. Jeśli na kontrolowanym odcinku badane spoiny nie mają poziomu jakości zalecanego dla danej klasy wykonania, to badania należy rozszerzyć na dwa odcinki o długości 900 mm położone po obu stronach odcinka z defektami. W przypadku wykrycia w tych spoinach dalszych NS należy ustalić przyczynę ich występowania.

Kryteria akceptacji NS przyjmuje się według normy [9], która określa wymagania trzech poziomów jakości D, C i B dotyczących klas wykonania EXC1, EXC2 i EXC3. Natomiast w przypadku klasy wykonania EXC4 norma PN-EN 1090-2 [11] wprowadziła dodatkowy poziom jakości B+, który jest poziomem jakości B z dodatkowymi wymaganiami podanymi w tablicy 17 (tabl. III). W tablicy podano również wymagania dodatkowe dotyczące pomostów stalowych w mostach [11]. Takie same wymagania dotyczące pomostów ortotropowych podano w tablicy C5 normy PN-EN 1993-2:2010 [12]. Zaskakującym jest fakt, że spoiny pomostów wg obu norm mają zróżnicowane zakresy ich badań NDT.

\section{Zmiana wymogów spawalniczych w PN-EN ISO 5817 i PN-EN 1993-1-1}

Kategoria użytkowania według PN-EN 1090-2 charakteryzuje obiekt pod względem warunków użytkowania. Nowe wydanie PN-EN ISO 5817 zastępuje od 30 kwietnia 2014 r. jej wydanie z 2009 r. Norma ta zawiera dodatkowy załącznik C (informacyjny), w którym podano wymagania dotyczące spoin w konstrukcji narażonej na zmęczenie. Dotyczą one poziomów jakości spełniających kryteria klasy zmęczenia FAT (fatigue class).

Wartość klasy zmęczenia FAT to zakres zmienności naprężeń $\Delta \sigma_{c}$ w odniesieniu do 2-milionowej liczby cykli $\left(\mathrm{N}_{\mathrm{c}}\right)$ ustalonej przy $75 \%$ granicy tolerancji ufności średniej z $95 \%$ prawdopodobieństwem przetrwania, z uwzględnieniem odchylenia standardowego, wielkości próby oraz wpływu naprężeń własnych. W odniesieniu do spoin jakości C i B w tablicy IV podano odpowiednie klasy zmęczenia FAT. Poziom C63 dotyczy FAT63 i niższego $\left(\Delta \sigma_{c} \leq 63 \mathrm{MPa}\right)$. Poziom B90 dotyczy FAT90 i niższych $\left(63<\Delta \sigma_{\mathrm{c}} \leq 90 \mathrm{MPa}\right)$, a B125 dotyczy FAT125 i niższych $\left(90<\Delta \sigma_{c} \leq 125 \mathrm{MPa}\right)$. Poziomy C63 i B90 obejmują zarówno spoiny czołowe, jak i pachwinowe, a poziom B125 wyłącznie spoiny czołowe.

Jednocześnie z wyżej omówionymi zmianami wymogów spawalniczych, wprowadzonych przez normę [9] (zatwierdzoną przez PKN 30 kwietnia 2014 r.), nastąpiła w Załączniku C do PN-EN 1993-1-1 [13] zmiana w ustalaniu klas wykonania (zatwierdzona przez PKN 24 lipca 2014 r.) - tablica V. Czynniki determinujące ten wybór (RC lub CC) dotyczą konstrukcji budowlanej obciążonej statycznie lub zmęczeniowo. Prawdopodobnym jest, że wprowadzenie tych zmian nastąpiło w wyniku wielu krytycznych uwag odnośnie wymogów dotyczących niezgodności spawalniczych NS w klasie wy-

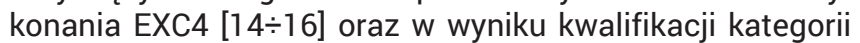
użytkowej mostów (por. tabl. 10) w funkcji klas zmęczenia FAT $[8,15,17]$. Według autorów błędem jest, że pominięto $w$ tym rozumowaniu fakt stosowania spoin poziomu jakości B+ w pomostach ortotropowych (por. tabl. III) [11]. Wątpliwości dotyczą również zakresu badań NDT II etapu wg tablicy II. Czy w zaistniałych warunkach nie należy zwiększyć zakresu badań spoin klasy wykonania EXC3?

Tablica I. Zależności przy ustalaniu klas wykonania (por. tabl. B.3 [11])

Table I. Recommended matrix for determining execution classes (see Table B.3 [11])

\begin{tabular}{|c|c|c|c|c|c|c|c|}
\hline \multirow{2}{*}{\multicolumn{2}{|c|}{$\begin{array}{c}\text { Klasy konsekwencji } \\
\text { Kategorie użytkowania }\end{array}$}} & \multicolumn{2}{|c|}{$\mathrm{CC1}$} & \multicolumn{2}{|c|}{$(\mathrm{CC} 2)$} & \multicolumn{2}{|c|}{ (CC3) } \\
\hline & & \multirow{2}{*}{$\frac{\mathrm{SC1}}{\mathrm{EXC1}}$} & \multirow{2}{*}{$\begin{array}{c}\text { SC2 } \\
\text { EXC2 }\end{array}$} & \multirow{2}{*}{$\frac{(\mathrm{SC} 1)}{(\mathrm{EXC} 2)}$} & \multirow{2}{*}{$\begin{array}{l}(\mathrm{SC} 2) \\
\mathrm{EXC3}\end{array}$} & \multirow{2}{*}{$\begin{array}{c}\mathrm{SC} 1 \\
\mathrm{EXC3}\end{array}$} & \multirow{2}{*}{$\begin{array}{l}(\mathrm{SC} 2) \\
\mathrm{EXC3}\end{array}$} \\
\hline Kategorie & (PC1) & & & & & & \\
\hline produkcJl & (PC2) & EXC2 & EXC2 & EXC2 & (EXC3) & EXC3 & (EXC4) \\
\hline
\end{tabular}

Tablica II. Zakres badań NDT II etapu (por. tabl. 24 [11])

Table II. Extent of NDT tests for the II stage (see Table 24 [11])

\begin{tabular}{|c|c|c|c|}
\hline \multirow{2}{*}{ Rodzaj spoin } & \multicolumn{3}{|c|}{ Spoiny warsztatowe lub montażowe, \% } \\
\hline & EXC2 & EXC3 & EXC4 \\
\hline $\begin{array}{r}\text { Poprzeczne rozciągane spoiny czołowe } \\
\text { z pełnym i niepełnym przetopem: } \sigma \geq 0,50 f_{\mathrm{y}} \\
\sigma<0,50 \mathrm{f}_{\mathrm{y}}\end{array}$ & $\begin{array}{c}10 \\
0\end{array}$ & $\begin{array}{l}20 \\
10 \\
\end{array}$ & $\begin{array}{c}100 \\
50\end{array}$ \\
\hline $\begin{array}{l}\text { Poprzeczne spoiny czołowe z pełnym i niepełnym przetopem: } \\
\qquad \text { w złączach krzyżowych } \\
\text { w złączach T }\end{array}$ & $\begin{array}{c}10 \\
5\end{array}$ & $\begin{array}{l}20 \\
10\end{array}$ & $\begin{array}{c}100 \\
50\end{array}$ \\
\hline $\begin{array}{l}\text { Poprzeczne spoiny pachwinowe rozciągane lub ścinane: } \\
\qquad \begin{array}{l}\text { gdy a }>12 \mathrm{~mm} \text { lub } t>20 \mathrm{~mm} \\
\text { gdy a } \leq 12 \mathrm{~mm} \text { i } t \leq 20 \mathrm{~mm}\end{array}\end{array}$ & $\begin{array}{l}5 \\
0\end{array}$ & $\begin{array}{c}10 \\
5\end{array}$ & $\begin{array}{l}20 \\
10\end{array}$ \\
\hline Spoiny podłużne i do usztywnień (żeber) & 0 & 5 & 10 \\
\hline
\end{tabular}


Tablica III. Wymiary graniczne NS w spoinach czołowych o poziomie jakości C, B i B+ Table III. Boundary dimensions of WI on butt welds for quality level C, B and B +

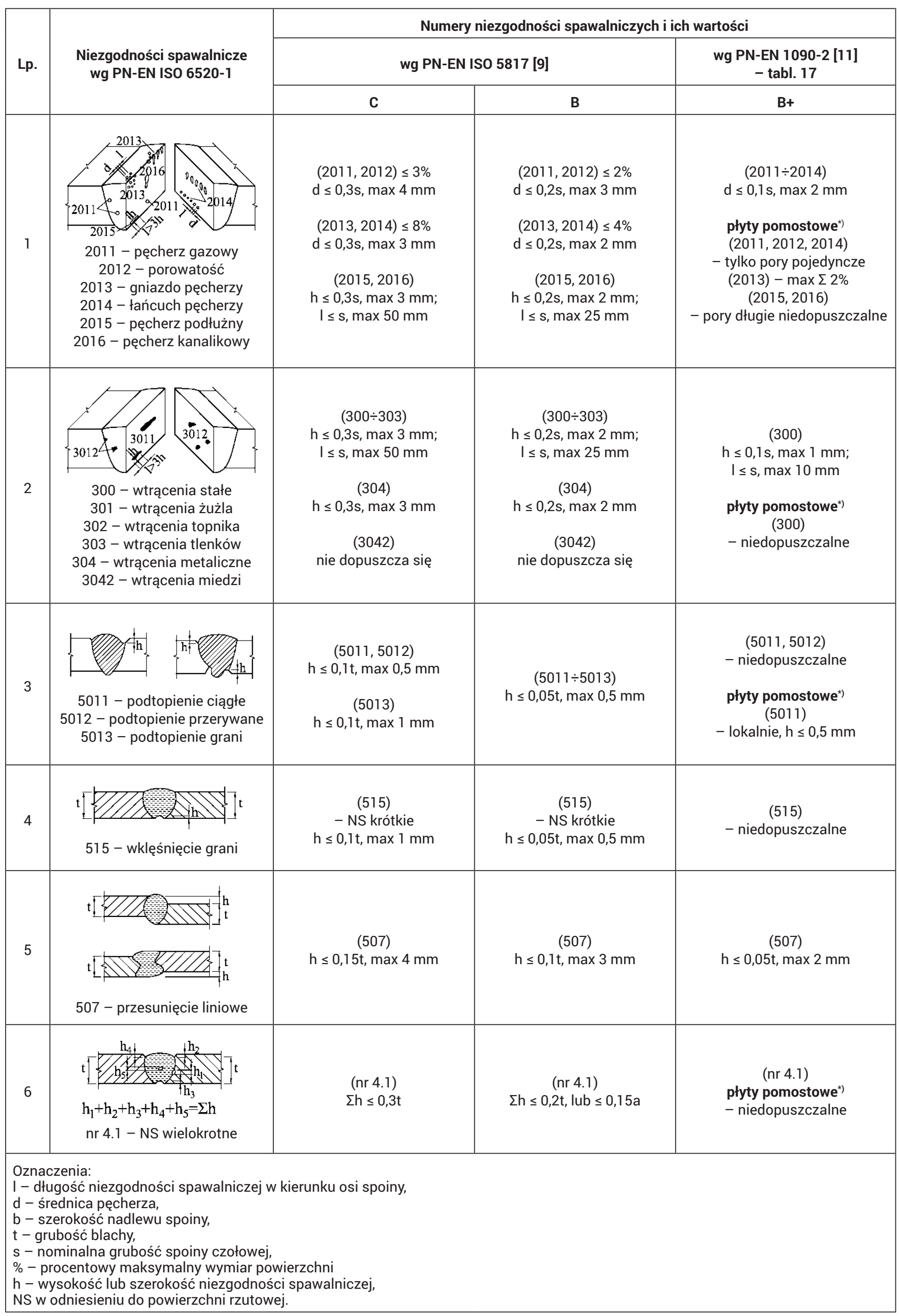


Tablica IV. Dodatkowe wymagania w odniesieniu do spoin czołowych narażonych na obciążenie zmęczeniowe (por. tabl. 4 i tabl. C.1 [9]) Table IV. Additional requirements for butt welds subjected to fatigue load (see Table 4 and Table C.1 [9])

\begin{tabular}{|c|c|c|c|c|c|}
\hline \multirow{2}{*}{$\mathrm{Nr}[3]$} & \multirow{2}{*}{$\begin{array}{l}\text { Niezgodności spawalnicze } \\
\text { wg PN-EN ISO 6520-1 }\end{array}$} & \multirow{2}{*}{$\mathrm{t}[\mathrm{mm}]$} & \multicolumn{3}{|c|}{ Graniczne niezgodności spawalnicze dla poziomów jakości } \\
\hline & & & $C 63^{c)}$ & $\mathrm{B9} 0^{\mathrm{c})}$ & B125 \\
\hline 2.3 & $\begin{array}{l}2011 \text { - pęcherz gazowy } \\
2012 \text { - pęcherze równomiernie rozłożone }\end{array}$ & $\geq 0,5$ & $a$ & $a$ & $\begin{array}{l}\text { - } \quad \text { dla pojedynczej warstwy } \leq 1 \% \\
\text { - } d \text { la wielu warstw } \leq 2 \% \\
\mathrm{~d} \leq 0,1 \mathrm{~s}, \max 1 \mathrm{~mm}\end{array}$ \\
\hline 2.4 & 2013 - gniazdo pęcherzy & $\geq 0,5$ & a & $\begin{array}{c}\leq 3 \% \mathrm{~d}) \\
\mathrm{d} \leq 0,2 \mathrm{~s}, \leq 0,2 \mathrm{a} ; \mathrm{d} \leq 2,5 \mathrm{~mm}\end{array}$ & $\begin{array}{l}\quad \leq 2 \% \text { d) } \\
\mathrm{d} \leq 0,1 \mathrm{~s}, \max 0,5 \mathrm{~mm}\end{array}$ \\
\hline 2.5 & 2014 - łańcuch pęcherzy & $\geq 0,5$ & a & a & $\begin{array}{l}\text { - dla pojedynczej warstwy } \leq 1 \% \text { d) } \\
\text { - dla wielu warstw } \leq 2 \% \text { d) } \\
\qquad d \leq 0,1 \mathrm{~s}, \max 1 \mathrm{~mm}\end{array}$ \\
\hline 2.6 & $\begin{array}{l}2015 \text { - pęcherz podłużny } \\
2016 \text { - pęcherz kanalikowy }\end{array}$ & $\geq 0,5$ & a & $\begin{array}{l}\mathrm{h} \leq 0,2 \mathrm{~s}, \leq 0,2 \mathrm{a} \\
\max \mathrm{h} \leq 2 \mathrm{~mm} \\
\max \mathrm{I}=2,5 \mathrm{~mm}\end{array}$ & nie dopuszcza się \\
\hline 2.9 & $\begin{array}{l}300 \text { - wtrącenia stałe } \\
301 \text { - wtrącenia żużla } \\
302 \text { - wtrącenia topnika } \\
303 \text { - wtrącenia tlenków }\end{array}$ & $\geq 0,5$ & $a$ & $\begin{array}{l}\mathrm{h} \leq 0,2 \mathrm{~s}, \leq 0,2 \mathrm{a} \\
\max \mathrm{h}=2 \mathrm{~mm} \\
\max \mathrm{I}=2,5 \mathrm{~mm}\end{array}$ & nie dopuszcza się \\
\hline \multirow{2}{*}{3.1} & 5071 - przesunięcie liniowe płyt & $\geq 0,5$ & a & $\mathrm{h} \leq 0,1 \mathrm{t} ; \max 3 \mathrm{~mm}$ & $\mathrm{~h} \leq 0,05 \mathrm{t} ; \max 1,5 \mathrm{~mm}$ \\
\hline & 5072 - przesunięcie liniowe rur & $\geq 0,5$ & a & $\mathrm{h} \leq 0,5 \mathrm{t} ; \max 1 \mathrm{~mm}$ & nie dopuszcza się \\
\hline- & 508 - przesunięcie kątowe & $\geq 0,5$ & $\beta \leq 2^{\circ}$ & $\beta \leq 1^{\circ}$ & $\beta \leq 1^{\circ}$ \\
\hline 1.5 & 401 - przyklejenie & $\geq 0,5$ & a & a & a \\
\hline 1.7 & $\begin{array}{l}5011 \text { - podtopienie ciągłe } \\
5012 \text { - podtopienie przerywane }\end{array}$ & $>3$ & a & a & nie dopuszcza się \\
\hline 1.8 & 5013 - podtopienie grani & $>3$ & a & a & nie dopuszcza się \\
\hline 1.9 & 502 - nadlew (spoina czołowa) & $\geq 0,5$ & a & a & $\mathrm{h} \leq 0,2 \mathrm{~mm}+0,1 \mathrm{~b}$ \\
\hline 1.11 & 504 - wyciek & $>3$ & a & a & $\begin{array}{c}\mathrm{h} \leq 0,2 \mathrm{~mm}+0,05 \mathrm{~b} \\
\max 1 \mathrm{~mm}\end{array}$ \\
\hline 1.12 & 505 - niewłaściwy brzeg spoiny & $\geq 0,5$ & $a$ & a & a \\
\hline- & $\begin{array}{l}5052 \text { - niewłaściwy } \\
\text { promień brzegu spoiny }\end{array}$ & $\geq 0,5$ & $b$ & b & $\mathrm{r} \geq 4 \mathrm{~mm}$ \\
\hline 1.14 & $\begin{array}{l}509 \text { - zwis } \\
511 \text { - wklęśnięcie lica }\end{array}$ & $>3$ & a & a & nie dopuszcza się \\
\hline 1.17 & 515 - wklęśnięcie grani & $>3$ & a & a & nie dopuszcza się \\
\hline 1.23 & 602 - rozpryski & $\geq 0,5$ & a & a & nie dopuszcza się \\
\hline $\begin{array}{l}\text { a - pos } \\
\text { b - nie } \\
\text { c) warto } \\
\text { d) granic }\end{array}$ & $\begin{array}{l}\text { zególne wartości dla danego poziomu B i C z tat } \\
\text { reśla się; } \\
\text { i z [17]; } \\
\text { ee wartości sumy różnych pęcherzy odniesionej }\end{array}$ & owi & 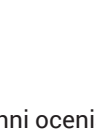 & & \\
\hline
\end{tabular}


Tablica V. Dobór klasy wykonania - EXC (por. tabl. C.1 [13])

Table V. Selection of execution class - EXC (see table C.1 [13])

\begin{tabular}{|c|c|c|}
\hline \multirow{2}{*}{$\begin{array}{c}\text { Klasa niezawodności (RC) } \\
\text { lub } \\
\text { Klasa konsekwencji (CC) }\end{array}$} & \multicolumn{2}{|c|}{ Rodzaj obciążenia } \\
\hline & $\begin{array}{l}\text { Statyczne, quasi-statyczne } \\
\text { lub sejsmiczne, gdy } \mathrm{DCL}^{\mathrm{a}}\end{array}$ & $\begin{array}{c}\text { Zmęczeniowe }{ }^{\mathrm{b}} \text { lub sejsmiczne, gdy DCM } \\
\text { lub } \mathrm{DCH}^{\mathrm{a}}\end{array}$ \\
\hline RC3 lub CC3 & $\mathrm{EXC3}^{\mathrm{C}}$ & $\mathrm{EXC3}^{\mathrm{C}}$ \\
\hline RC2 lub CC2 & EXC2 & EXC3 \\
\hline $\mathrm{RC} 1$ lub CC1 & EXC1 & EXC2 \\
\hline \multicolumn{3}{|c|}{$\begin{array}{l}\text { a Sejsmiczne klasy ciągliwości: Niska = DCL, Średnia = DCM; Wysoka = DCH } \\
\text { 'b Patrz EN 1993-1-9 } \\
\text { ' W przypadku ekstremalnych konsekwencji zniszczenia może być stosowana klasa EXC4 }\end{array}$} \\
\hline
\end{tabular}

\section{Podsumowanie}

Dla wielu normy europejskie dotyczące projektowania budowlanego są coraz mniej przejrzyste i niezrozumiałe. Nowe wymagania wyznaczone zostały bez pełnego literaturowego rozpoznania zagadnienia, bez analizy wyników badań modelowych i bez analizy wyników badań analogicznych rozwiązań literaturowych.

Przykładowo dwie normy PN-EN 1090-2:2012 [11] oraz PN-EN 1993-2:2010 [12], wydane w odstępie jednorocznym, przedstawiają wymogi dotyczące analogicznych spoin czołowych w pomostach ortotropowych o sprzecznych zaleceniach obliczeniowych. Norma dla mostów stalowych [12] zezwala przy zalecanych i podanych grubościach blachy poziomej pomostu na rezygnację z obliczania w nich momentów zginających. Jednocześnie w tym samym Załączniku C wprowadza zaostrzone wymagania dotyczące spoin blach poziomych oraz uzależnia zakres ich badań od wartości występujących w nich naprężeń, a przy $\sigma \leq 0,75 f_{y}$ zezwala na $50 \%$ badania wizualne (VT) oraz przy $\sigma>0,60 f_{y}$ na $10 \%$ badania radiograficzne (RT). Jak określić poziom jakości $B+$ tych spoin, gdy nie są one badane radiograficznie, a nawet wizualnie?

W chwili obecnej powołane są 22 naprawcze grupy robocze złożone z ekspertów 34 państw, członków CEN. Nowa, druga, poprawiona i zmieniona edycja Eurokodów EC3 i EC4 zapowiadana jest na koniec 2020 r. i uwzględni zbierane od kilku lat propozycje poprawek. Przykładowo do poddanego ocenie drugiego szkicu prEN 1993-1-1 v.2 wpłynęło 440 propozycji zmian, a do prEN 1993-1-8 v.2 620 propozycji zmian.

\section{Literatura}

[1] Klimpel A.: Kontrola i zapewnienie jakości w spawalnictwie. Tom 1, Wydawnictwo Politechniki Śląskiej, Gliwice 1998.

[2] Wichtowski B.: Wytrzymałość zmęczeniowa spawanych złączy doczołowych w stalowych mostach kolejowych. PN Politechniki Szczecińskiej, nr 572, Szczecin 2002.

[3] Wichtowski B., Czajkowski T.: Ocena jakości spawanych złączy doczołowych w mostach kolejowych według norm europejskich, Inżynieria i Budownictwo, $\mathrm{nr} 2,2006$.

[4] PN-89/S-10050 Obiekty mostowe - Konstrukcje stalowe - Wymagania i badania.

[5] PN-87/M-69772 Spawalnictwo - Klasyfikacja wadliwości złączy na podstawie radiogramów.

[6] Ustawa z 12 września 2002 r. o normalizacji (Dz. U. z 2015 r., poz. 1483).

[7] Hobbacher A.: Recommendations for fatigue design of welded joints and components. IIW Doc. XIII-1539-96, Updated June 2002.

[8] PN-EN 25817:1997 Złącza stalowe spawane łukowo - Wytyczne do określania poziomów jakości według niezgodności spawalniczych.

[9] PN-EN ISO 5817:2014 Spawanie - Złącza spawane ze stali, niklu, tytanu i ich stopów (z wyjątkiem spawanych wiązką) - Poziomy jakości według niezgodności spawalniczych.

[10] Wichtowski B., Smułczyński E.: Poziomy jakości spawanych złączy doczołowych według normy PN-EN ISO 5817,2007" Biuletyn Instytutu Spawalnictwa w Gliwicach, nr 6, 2008.

[11] PN-EN 1090-2:2012 Wykonanie konstrukcji stalowych i aluminiowych - Część 2: Wymagania techniczne dotyczące konstrukcji stalowych.

[12] PN-EN 1993-2:2010 Eurokod 3 - Projektowanie konstrukcji stalowych - Część 2: Mosty stalowe.

[13] PN-EN 1993-1-1:2006/A1:2014 Eurokod 3 - Projektowanie konstrukcji stalowych - Część 1-1: Reguły ogólne i reguły dla budynków.

[14] Wichtowski B., Hołowaty J.: Badania złączy spawanych w mostach stalowych według wymagań norm PN-EN 1090-2 i PN-EN ISO 5817, Inżynieria i Budownictwo, nr 2, 2016.

[15] Hołowaty J., Wichtowski B.: Testing of welded joints in steel bridges to European Standards. 8th International Symposium of Steel Bridges, Innovation \& New Challenges, Istanbul 2015.

[16] Czuchryj I., Sikora S., Staniszewski K.: Ocena jakości złączy spawanych w konstrukcjach stalowych kontrolowanych radiograficznie na podstawie poziomu jakości B+ wg PN-EN 1090-2, Przegląd Spawalnictwa, nr 3, 2013.

[17] Wichtowski B., Hołowaty J.: Jakość spoin czołowych w mostach w funkcji klas zmęczenia według norm europejskich i badań własnych, Inżynieria i Budownictwo, nr 9, 2016. 